\title{
ACERCAMIENTOS AL GRABADO
}

\author{
Approaches to engraving
}

Francisco Hernández Chavarría*

Ólger Arias**

\begin{abstract}
RESUMEN
El trabajo del grabador inicia con una matriz, en la cual transfiere un diseño, que de acuerdo con la técnica, se graba en una placa de metal, se talla en la madera, se estabiliza en la superficie de una placa de mármol o se pinta en una pantalla de serigrafía bloqueándola selectivamente. Finalmente, esa matriz se impregna en tinta e imprime en papel, tela u otro soporte. Esa imagen impresa es lo que llamamos grabado, con el epíteto otorgado por la matriz, ya sea grabado en metal, xilografía, litografía y serigrafía, respectivamente. El artista decide el número de impresiones que realiza de cada matriz y cada una de esas impresiones es un grabado original y el total se conoce como edición; por eso el grabado se llama el arte del original múltiple.
\end{abstract}

Palabras clave: Grabado en metal, xilografía, litografía, serigrafía, grabado no tóxico, original múltiple.

\begin{abstract}
The work of printmaker begins with a matrix, in which a design is transferred. According with the technique the design is etched on the metal plate, is carved on the wood, is stabilized on the surface of a marble plate, or is painted on the serigraph screen blocking it selectively. Then, the matrix is inked and printed on paper, fabric or other support. That printed image is what we call print with an epithet bestowed by the nature of the matrix, such as etching, xylographic, lithography, and silkscreen or serigraphic, respectively. The artist decides the number of impressions that he or she is going to make from each matrix, and each one is an original print; also, the totally of that prints is known as an edition; for that reason, the printmaking is called the arts of multiple originals.
\end{abstract}

Key Words: Etching, xylograph, lithograph, silkscreen, serigraph, non-toxic etching, multiple original.

\footnotetext{
* Universidad de Costa Rica. Escuela de Artes Plásticas. Costa Rica

Correo electrónico: franciscohernandezch@gmail.com

** Universidad de Costa Rica. Subdirector Escuela de Bellas Artes. Costa Rica.

Correo electrónico: oarias09@yahoo.com.mx
}

Recepción: 8/12/2015. Aceptación: 3/8/2016. 


\section{Introducción}

La gran depresión económica de 1929, indirectamente catapultó el grabado, pues era una manifestación artística que cumplía al pie de la letra con la definición de "arte para millones", promulgada en el "New Deal" de la administración Roosevelt, que condujo, en 1935, al establecimiento de la División de Artes Gráficas, del Works Progress Administration's Federal Art Project; cuyas manifestaciones artísticas más progresivas fueron en las técnicas de litografía, serigrafía, xilografía y un tanto menos en grabado en metal, porque en aquella época se le consideraba una manifestación elitista por los altos costos del proceso. El efecto directo del carácter multi-original del grabado, llevó a exposiciones simultáneas en diversas ciudades de EEUU (Langa, 2004: 5).

Actualmente, el grabado es una de las manifestaciones artísticas de nuestro tiempo, y es tan vigente como la pintura y la escultura y para hacer esta aseveración, transcribimos un fragmento de la introducción del libro The Contemporary Print: From Pre-Pop to Postmodern, de Susan Tallman (1996: 7):

El grabado actualmente es una de las formas de arte más exitosas y a la vez menospreciadas. Entre 1960 y la actualidad, el grabado se ha movido de los márgenes de la producción artística a su centro. Ya no es una especialidad técnica aislada, el grabado es actualmente una parte estándar de muchas carreras artísticas [...] y ocupa espacios en las paredes, anteriormente ocupados por la pintura.

El texto citado anteriormente hace alusión a la segunda mitad del siglo XX; sin embargo, ese cambio en la concepción artística tuvo sus raíces unos cien años antes, cuando la fotografía comenzó a desplazar al grabado en la ilustración de textos. Hoy, especialmente para las generaciones más recientes, es difícil imaginar la cotidianidad sin imágenes generadas al momento, pues tenemos acceso a una infinidad de dispositivos fotográficos; pero no siempre fue así; hubo una época en que la ilustración de un texto se iniciaba en el taller de grabado y por lo tanto, el grabado se asociaba con las imágenes ilustrativas de textos, más que con obras de arte. Por ello, haremos un breve recorrido por la historia del grabado, que a su vez, al menos en sus inicios, se traslapa con la historia de la ilustración impresa y aunque esa concepción cambió radicalmente, una gran mayoría de la población, sin la menor duda, reconoce a la pintura y a la escultura como parte de las artes plásticas; pero desconoce los principioa básicos, definiciones y lexicografiá del grabado; ante tales argumentos, es importante abocarse a un conocimiento más amplio del grabado, que sirva como base para una mejor comprensión de la obra y por lo tanto, para disfrutarla en sus múltiples modalidades, lo cual es el objetivo de este trabajo.

\section{El grabado en los albores de la imprenta}

La razón para esa marginalidad del grabado entre las artes plásticas radica en su propia historia, pues su apogeo inicial, a mediados del siglo XV, coincide con la invención de la imprenta y ambos se unirían por los siguientes cuatrocientos años, como un matrimonio inseparable, para catapultar el conocimiento en Occidente, colocando a la imprenta en el sitial referencial, como el invento más trascendental de los dos últimos milenios. Si bien, en ese sentido se le brindan todos los créditos a la imprenta, debemos reconocer, que los textos sin las imágenes ilustrativas no hubiesen tenido gran impacto y para afirmar tal hecho, basta con pensar en una carta de navegación, las fases de la luna, un texto geográfico o astronómico e incluso la descripción de cualquier especímen biológico. En estos ejemplos, como en muchos otros casos, las imágenes complementan y dan sentido al texto.

En ese contexto histórico, debemos tener presente que antes de la imprenta, los libros eran escritos e ilustrados a mano. El texto era fielmente copiado, pero no siempre ocurría lo mismo con las imágenes, ya que sutilmente iban cambiando de ilustrador a ilustrador, de acuerdo con su habilidad para dibujar y al cabo de muchas copias, los cambios podían ser muy 
significativos; pensemos por un momento en una ilustración científica, como la descripción taxonómica de un espécimen en la cual, esos sutiles cambios podrían conducir a catalogarle en una especie diferente y hasta en otro género.

Con la invención de la imprenta, los libros comenzaron a imprimirse a una velocidad nunca antes vista hasta ese momento; pero, surgía la necesidad de ilustrarlos a la misma velocidad y con imágenes idénticas, lo que Ivins (1975:13), denominó “manifestaciones gráficas exactamente repetibles". Fue entonces cuando el grabado se convirtió en el aliado de la imprenta; primero fue la xilografía y luego el grabado en metal. Aunque la estética y la maestría en la ejecución de esos grabados nos sigue cautivando, en esencia, eran ilustraciones. Se grababan imágenes religiosas e incluso paisajes, que hoy serían equivalentes a las tarjetas postales o souvenirs; por lo tanto, el valor artístico de esas imágenes era secundario, tal como ocurre actualmente con las ilustraciones.

Las técnicas de grabado mencionadas, xilografía y grabado en metal, como formas de la ilustración, comenzaron a ser desplazadas a inicios del siglo XIX por la litografía, un proceso inventado en 1798 por Alois Senefelder (1819: 1-85), quien descubrió la forma de grabar una imagen en una placa de mármol, la cual podía ser entintada y transferida a un soporte, como el papel. El proceso resultó tan exitoso que pronto fue el método usual de ilustración. Sin embargo, ya en los inicios del siglo XIX, se comenzaba a perfeccionar la fotografía, que sería concebida como el método más práctico para captar imágenes. Así, el primer libro ilustrado con fotografías, que muestra su potencial, fue The pencil of nature, de William Henry Fox Talbot (1844: 63). Y ya, en el siglo XX, los avances tecnológicos en la fotografía la fueron simplificando y haciéndola cada vez más asequible al público general; así, pasó de las placas fotográficas en vidrio, a las películas en acetato de celulosa y de estas a la fotografía digital, para convertirse en parte de nuestra cotidianidad. Podríamos acotar, que ese matrimonio prácticamente indisoluble de la imprenta y el grabado, fue disuelto por la fotografía.

A medida que el grabado de ilustración era relegado a un segundo plano, los artistas vertieron su interés en él, como una forma de expresarse, lo que tomó auge a mediados del siglo XIX, con un grupo de pintores franceses que se hicieron llamar "Pintores grabadores", con lo cual se distanciaban del grabado de ilustración y aceptaban el grabado como una nueva estética y como una ruptura con el pasado. No obstante, en las diferentes épocas del grabado, siempre hubo grabadores que lo utilizaron para su expresión artística y los dos mejores ejemplos son Rembrandt (1606-1669) y Goya (1746-1828).

\section{3. ¿Qué es el grabado?}

Luego de esta breve incursión histórica en el grabado, es importante definir y ahondar un poco en él y sus múltiples variables, así como en su lexicografía. En esencia, el grabado es el arte de plasmar un diseño en la superficie de un medio, que en términos generales se denomina "matriz"; la cual, luego es entintada y ese diseño se imprime en un soporte, usualmente el papel, pero puede ser tela u otro material y esta impresión es la que denominamos grabado y le ponemos un adjetivo calificativo, que indica la naturaleza de la matriz original. Por ejemplo, si es una pieza de madera, una placa metálica, una seda o bien, una placa de piedra caliza, la denominación para cada uno de esos casos, respectivamente, es: xilografía, grabado en metal, serigrafía y litografía. Incluso, actualmente se habla de impresión digital como otra expresión del grabado, cuando la matriz es una imagen digital que es procesada o intervenida por el artista.

El atributo fundamental del grabado, es que independientemente de la matriz en que se trabaje, de cada una de ellas se pueden hacer múltiples impresiones y cada una es un grabado original y ese conjunto se denomina "edición"; de ahí, la calificación de "original múltiple" con que se distingue al grabado. 


\section{4. ¿Qué es una edición?}

Una edición es la serie de impresiones que se hace a partir de la matriz creada por un artista del grabado. El número de impresiones lo define el artista y cada una equivale a un original.

El formato del grabado es muy variado, por ejemplo, las obras en gran formato superan el metro de altura; en contraposición, tenemos el pequeño formato y como ejemplo están muchos de los autorretratos de Rembrandt, que miden menos de $4 \mathrm{~cm}$ de altura.

En términos muy poéticos, se dice que el grabado democratizó el arte; esta afirmación se sustenta en ese carácter de original múltiple, pues permite que un mayor número de personas adquieran obras originales; lo que se contrapone a otras expresiones artísticas, que crean obra individual, como por ejemplo, la pintura.

Al pie de cada grabado de la edición aparece una información, que por convención internacional, se consigna en el siguiente orden: a la izquierda aparece un número a manera de fracción aritmética, cuyo "numerador", en realidad son los dígitos que indican el número de obras que componen esa edición; mientras que el dígito inferior, corresponde a la numeración específica de cada grabado; por ejemplo: 10/1, indica que la edición es de 10 ejemplares y que el que tenemos entre manos es el número 1. Luego, aparece el título de la obra y finalmente en el extremo derecho, la firma del artista y el año de realización de esa obra, en la figura 1 se puede apreciar esta terminología.

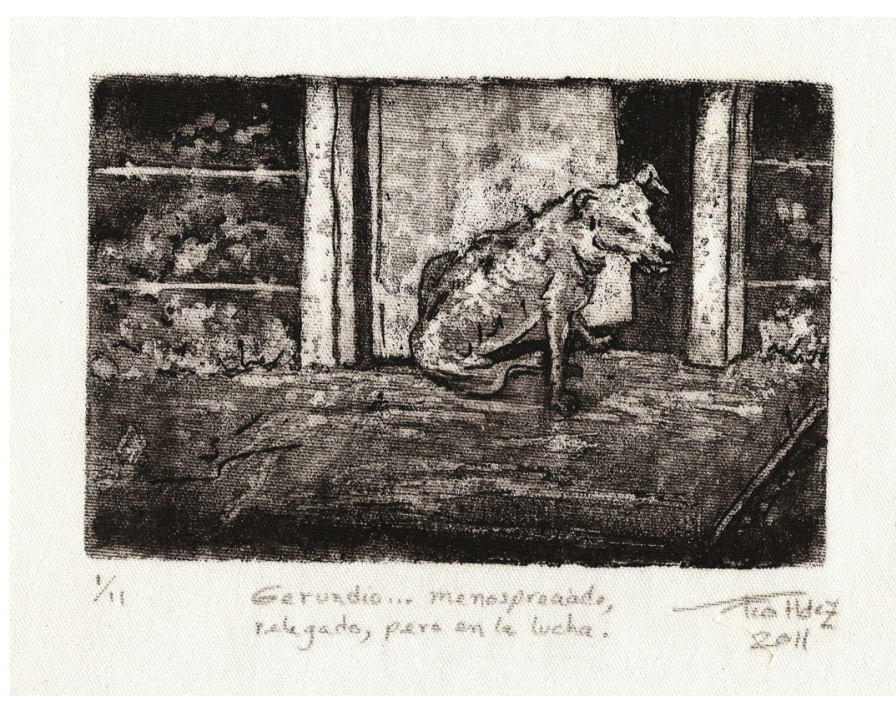

FIGURA 1.

Francisco Hernández. Gerundio... relegado, menospreciado, pero siempre en la lucha. 2011, grabado en metal, placa de aluminio, trabajado por electrólisis e impreso en lino, 13 x $20 \mathrm{~cm}$. 
Pueden aparecer otras siglas, usualmente provenientes de galicismos, dada la tradición francesa del grabado y que indican casos específicos; la más frecuente es $\mathrm{P} / \mathrm{A}$, que significa "prueba de artista" y que se utiliza para consignar grabados, que por alguna razón el artista no consideró como parte de la edición, como puede ser diferencias en el color, el entintado, etc., pero que las consideró buenas y por lo tanto, no las desechó.

Con esta información general sobre grabado, es importante ahondar en las principales modalidades de esta rama de las bellas artes.

\section{Xilografía}

La raíz latina xilo significa madera y corresponde a una sección del tallo leñoso de un árbol, que puede corresponder a un corte longitudinal o transversal; para efectos del grabado, en el primer caso, se trata de una tabla y en el segundo de un taco. En una tabla, se observan los cortes longitudinales de los anillos de crecimiento, que por estar formados por fibras aparecen como líneas o vetas, que los carpinteros denominan "el jaspe de la madera"; en tanto, en el taco, que corresponde al corte transversal, la estructura es más simple, pues las fibras aparecen como un punteado. Cuando el grabado se hace en una tabla, el artista puede explotar estéticamente las vetas de la madera, que se replican en el grabado xilográfico; un ejemplo es La niña y el viento (1969), de Francisco Amighetti, en el cual, las líneas de la madera representan al viento; en la figura 2 se muestra una resemantización de esa obra, titulada "La chica y el viento", en la cual se muestra ese efecto del viento, aprovechando las líneas de la madera.

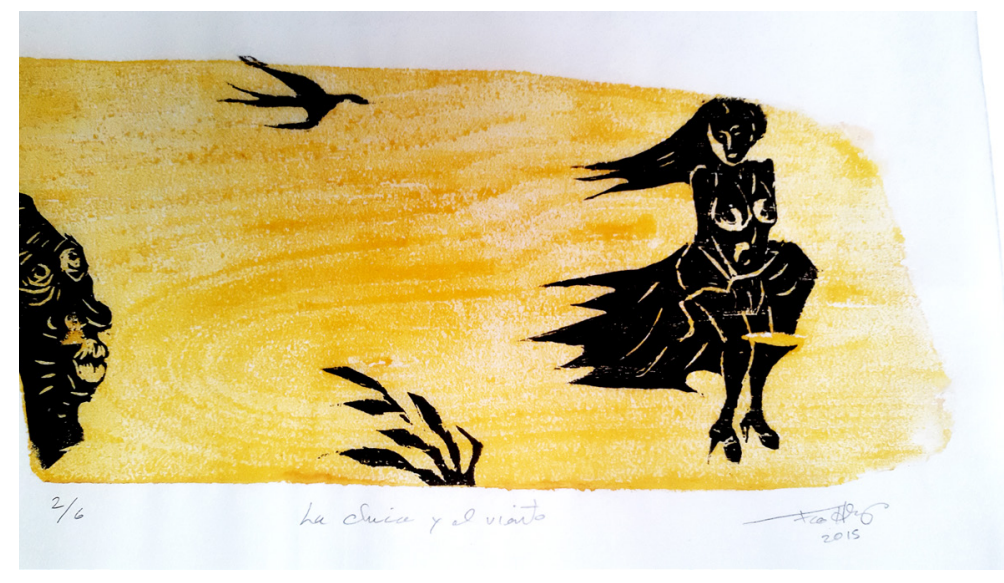

FIGURA 2.

Francisco Hernández. La chica y el viento, 2015, Cromoxilografía (matriz perdida), 24 x 35 cm.

Contrario a lo anterior, en el grabado al taco o "contra fibra", la madera presenta menos textura, porque esas líneas están cortadas transversalmente, por lo que se utiliza para un grabado con mayor detalle o en términos ópticos, con mayor resolución de imagen (Figura 3). 


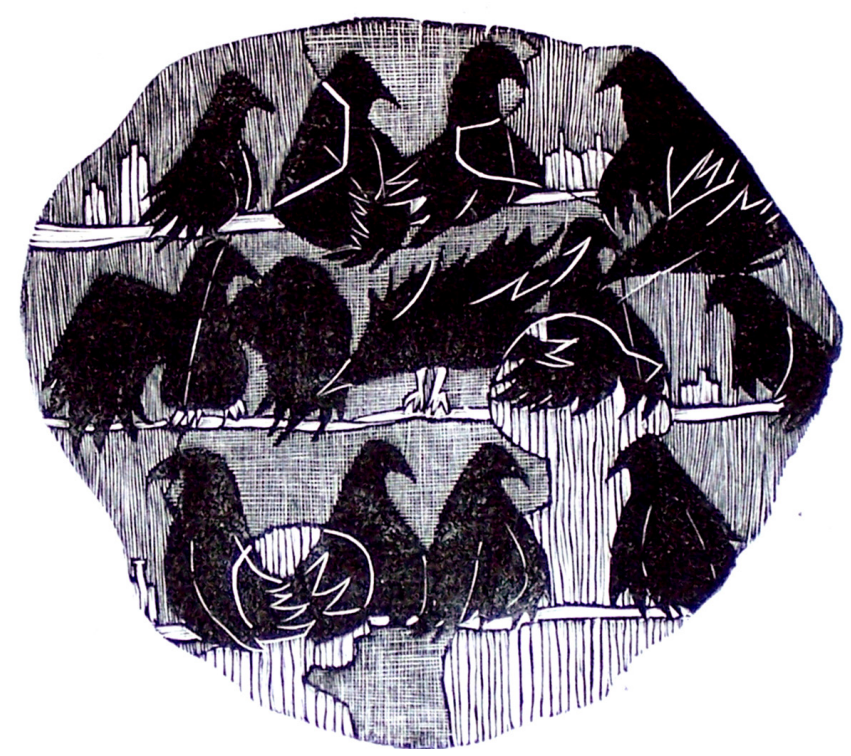

FIGURA 3.

Salomón Chávez. La estancia. 2014, xilografía al taco, 9 x 9,5 cm.

Estas características de la madera, según se trate de una tabla o un taco, hace que la xilografía respectiva posea características distintivas. En la tabla usualmente se trabaja con gubias con filo en forma de U o V, por lo cual, la presión, fuerza, soltura y espontaneidad ejercida, se refleja en surcos excavados, que corresponden a las líneas del grabado; por lo que este tipo de xilografía es muy expresiva. En tanto que el grabado al taco, la tradición indica que se debe trabajar con buriles, un tipo de herramienta con puntas más finas y que producen líneas delgadas y muy nítidas; aunque, actualmente puede emplearse cualquier otro instrumento, hasta taladros, con lo cual se logran efectos muy distintos del tradicional.

Independientemente del proceso de trabajo en la madera, la matriz suele entintarse con tinta negra e imprimirse sobre papel blanco, lo que brinda una imagen de trazos blancos sobre un fondo negro, que es característico de la xilografía. También, está la cromoxilografía, en la cual cada color usualmente corresponde a una tabla individual, de manera que la imagen final, con varios colores, se integra mediante impresiones secuenciales de las diferentes matrices; ese es el ejemplo en la figura 4, realizada por Alberto Murillo; sin embargo, puede ser una sola tabla en la que se inicia con el color más claro, que se imprime y se elimina esa sección, para volver a tallar la tabla e imprimir el siguiente color, hasta que finalmente quedan solo las secciones correspondientes al negro, por lo que esta técnica se denomina "la matriz perdia”; la figura 2, corresponde a esta técnica. 


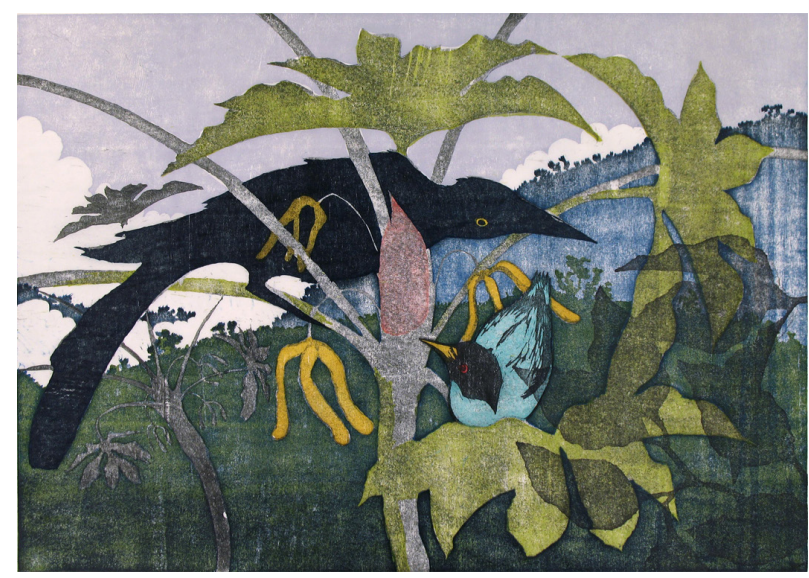

FIGURA 4.

Alberto Murillo. ¡Cuidado con el zanate!1999, cromoxilografía,113x $80 \mathrm{~cm}$.

\section{Grabado en metal o huecograbado}

Tradicionalmente los textos de grabado en metal señalan que sus inicios se remontan a los armeros de la Edad Media, quienes decoraban las armaduras, personalizándolas con diseños propios; no obstante, hay datos que prueban que ese inicio fue mucho antes y que data de finales de la Edad de Hierro, por ejemplo el museo de la Antigua Ágora, muestra petos corintios del siglo VII a. C. con imágenes grabadas.

El desarrollo histórico supone que el inicio propiamente del grabado, ocurrió cuando esas decoraciones, ya fuese de armaduras u otros objetos metálicos, fueron impresas en papel o cuero, posiblemente al principio fue un ardid de los armeros para conservar sus diseños. La denominación de huecograbado, se debe a que el diseño es horadado en la matriz metálica; aunque ocurre algo similar en la xilografía, el término se usa exclusivamente para el grabado en metal.

En este caso, la matriz es una pieza de metal, que por antonomasia era cobre; aunque luego se utilizó el hierro y el cinc y en los últimos decenios, los artistas emplean otros metales, producto de la industria, como el aluminio e incluso el acero inoxidable. El método consiste en recubrir ese metal con un barniz protector, sobre el cual se dibuja el diseño a grabar con un instrumento puntiagudo, que remueve el barniz de los trazos, dejando en ellos el metal expuesto; el cual luego es atacado por el medio para grabar. Desde los inicios del grabado hizo su aparición el ácido nítrico, para horadar el metal, aunque también se usaron otros mordientes como mezclas de sales en vinagre; sin embargo, para mediados del siglo XIX, el ácido nítrico fue adoptado como el favorito por los grabadores, dada su disponibilidad en el mercado, la velocidad de acción, su bajo precio y haciendo caso omiso de su peligrosidad, el ácido reinó en los talleres de grabado, durante gran parte del siglo XX. Afortunadamente, en la década de 1990, las políticas ecológicas y la bioseguridad calaron en la conciencia de los artistas y el grabado en metal entró en una modalidad "no tóxica" o "sin ácido" y estos dos términos han sido emblemáticos en lo que actualmente se considera una revolución en el grabado. Las dos modalidades libres de ácido más empleadas, son el grabado electrolítico y el 
empleo de mordentes salinos en una modalidad de grabado por óxido-reducción, para emplear el término químico de tales reacciones. En ambos casos, el resultado final es que las líneas del diseño dibujado sobre el barniz protector, son atacadas por la electricidad o el mordente, que remueve átomos de esa superficie hasta transformar las líneas en surcos de variable profundidad, de acuerdo con el deseo del artista (Hernández-Chavarría, 2014: 181).

El resultado es una placa metálica en cuya superficie se ha "excavado" un diseño, que puede consistir en un dibujo de solo líneas o combinar con zonas erosionadas, para crear un claroscuro (Figura 5a). En el primer caso, o sea en el dibujo con solo líneas, se denomina aguafuerte, como reminiscencia del pasado, cuando el mordente empleado tenía ese nombre; un maestro del aguafuerte, es Rembrandt, quien para lograr los claroscuros combinó las líneas de aguafuerte con líneas trazadas a mano, lo que se denomina "punta seca". Otra forma de lograr valores tonales para crear claroscuros, consiste en grabar áreas de la placa para erosionarlas; este método se denomina aguatinta, y se atribuye su autoría a Jean Baptiste Le Prince en 1768 , aunque el término había sido acuñado previamente (Astijnman, 2012: 213); uno de los claros exponentes de esta modalidad es Goya.

Una vez grabada la placa, como la mostrada en la figura 5a, el proceso de impresión consiste en entintarla y luego limpiarla de manera que la tinta queda retenida en las líneas excavadas o en las zona erosionadas y la cantidad retenida depende de la profundidad de la erosión, lo cual se traduce en valores tonales, desde grises muy tenues en zonas poco grabadas, hasta zonas negras en las áreas muy profundas o en las líneas; en tanto, en las zonas no grabadas la tinta se remueve, lo que equivale a las zonas blancas o de menor valor tonal, tal como se muestra en la figura $5 b$.

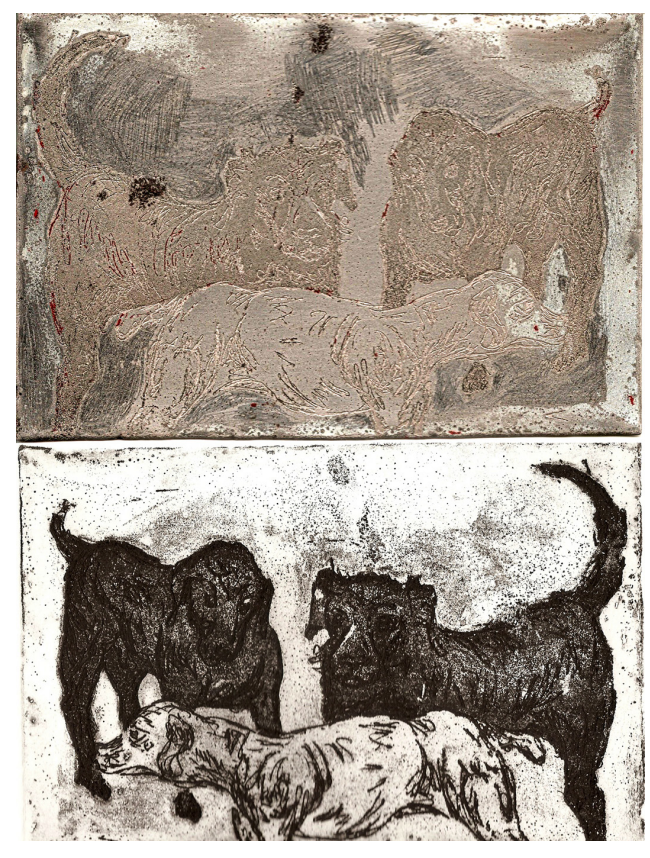

FIGURA 5.

Francisco Hernández. ¡Guauuu... qué linda! 2014, grabado en metal,12 x $18 \mathrm{~cm}$ (en la imagen superior [Fig. 5a] se muestra la placa de hierro grabada. La imagen inferior [Fig.5b] corresponde a la impresión de esa placa). 
Previamente hicimos alusión al grabado en blanco y negro; sin embargo, puede ser a color; para lo cual hay diversas opciones, como trabajar con varias placas y entintar selectivamente los distintos colores, lo que se conoce en el argot del grabado con el galicismo de "à la poupée", pues cada color se aplica con un cilindro de papel, denominado "muñequita" (Figura 6).

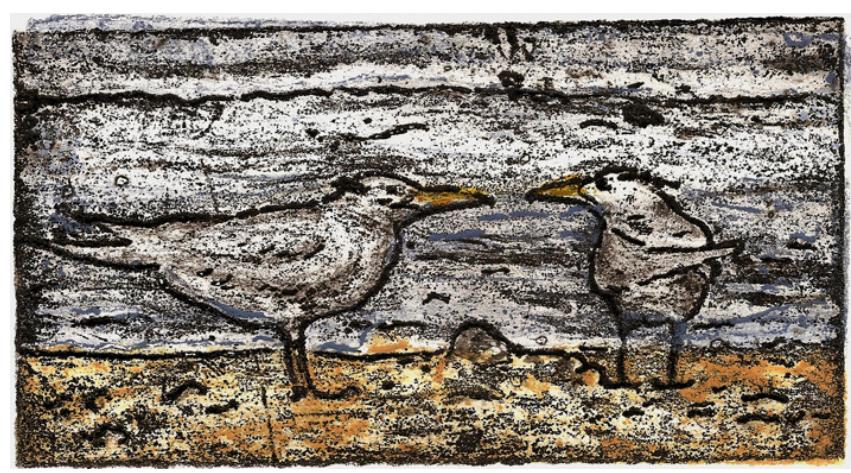

FIGURA 6.

Francisco Hernández. Amantes del mar. 2010, grabado en metal, con dos placas, entintado à la poupée, $10 \times 18 \mathrm{~cm}$.

Otras opciones para realizar grabados a color pueden ser más sofisticadas, en una de ellas se hace una separación de colores siguiendo el concepto de cuatricromía y se imprime cada color en una plancha separada, tal como trabaja el grabador nacional Rudy Espinoza; o bien, se pueden obtener diversos colores con la técnica de viscosidad, en la cual se trabaja con distintos relieves en la placa y tintas de diferente consistencia; también, entre otras opciones está la de colorear a mano cada impresión, lo que brinda un efecto más pictórico. En fin, hay una amplia variedad de opciones para el grabado a color.

\section{Litografía}

Como mencionamos previamente, la litografía fue inventada por Alois Senefelder y ello obedeció a un hecho fortuito y casual, que supo interpretar y aprovechar, lo cual corresponde a la definición de serendipia, un término bastante común en las ciencias, pero poco usado en arte (Hernández-Chavarría y Rivera, 2001: 6). Una descripción un tanto anecdótica de ese descubrimiento, muestra a Alois Senefelder, como un joven de pocos recursos económicos, estudiante de derecho, que ante la muerte de su padre tuvo que hacer frente a las obligaciones económicas del hogar, lo cual lo obligó a dejar sus estudios y tomar el trabajo de su padre, quien era actor. Buscando una entrada económica adicional, publicó una obra de teatro, pero, los costos de imprenta fueron muy altos, por lo cual pensó en idear un método que abaratara la publicación de libros y supuso que con grabado en metal lo lograría, si imprimía planchas que representaran las páginas de una futura publicación. Un problema que enfrentaba, era el hecho de que al imprimir una plancha la imagen se invierte, por lo que el texto debe escribirse de izquierda a derecha (esa inversión de la imagen se aprecia en la figura 5, pues la 
figura 5a corresponde a la plancha de metal grabada y la figura 5 b es la impresión de esa plancha, como se observa ambas son imágenes en espejo; por lo tanto, un texto debe escribirse de derecha a izquierda en la plancha metálica, para que al imprimirlo se inverta y pueda leerse normalmente). Para solucionar tal problema, Senefelder practicó la escritura inversa, pero dados sus limitados recursos económicos, no podía darse el lujo de practicar en láminas de cobre y por ello recurrió a piezas de mármol, que utilizaba como pizarra, escribiendo y borrando. Un día su madre le pidió que hiciera un recibo para la lavandera que esperaba en la puerta, para llevarse la ropa a lavar y como en ese momento no tenía papel a disposición, escribió la lista en el mármol, para transcribirla más tarde. Sin embargo, antes de borrar el texto se le ocurrió ponerle el mordente que usaba para el cobre, solo que diluido, y al borrar, notó algo diferente en la piedra; decidió pasarle tinta y ¡serendipia!, solo se entintaron las líneas escritas y al imprimir eso en un papel, tenía el texto con un fondo blanco. Había inventado la litografía (Senefelder, 1819: 1).

Para comprender la mecánica de ese proceso litográfico, es preciso tener en mente los principios químicos de miscibilidad y repulsión de sustancias. El primero se basa en el concepto de que "igual disuelve a igual"; así, las sustancias acuosas se disuelven fácilmente entre sí, como el agua y el vinagre; lo que se denomina hidrofilia. A la vez, las sustancias grasas también se disuelven entre sí, como los aceites, esto es lipofília (la raíz griega philos significa "amigo" y se usa para indicar afinidad). Por el contrario, las sustancias diferentes, como el agua y el aceite, se repelen entre sí y no se mezclan; así, una sustancia hidrofílica rechaza el aceite y eso se conoce como lipofóbico (la raíz griega phobos significa miedo y se usa para indicar repulsión). En conclusión, igual disuelve a igual y los opuestos se rechazan.

Resulta que el mármol es hidrofílico, o sea que tiene afinidad por el agua y rechaza la grasa; ocurre exactamente lo contrario con la tinta litográfica, que tiene afinidad por la grasa y rechaza el agua. Con esto en mente es fácilmente comprensible el proceso litográfico, pues se dibuja en el mármol con la tinta grasa, que se estabiliza dejando un fantasma de trazos lipofílicos. Por lo tanto, al entintar esa plancha de mármol con tinta grasa, esta se adsorbe solo en los trazos lipofílicos y es rechazada del resto de la superficie del mármol, que es hidrofílica; eso fue lo que Senefelder descubrió accidentalmente.

El proceso tuvo tal éxito, que pronto desplazó a la xilografía y al grabado en metal, como los métodos estándar para la ilustración. No obstante, algunos artistas comenzaron a utilizar la nueva técnica para expresarse artísticamente, como Goya, quien ya en su vejez, cercano a los 80 años, creó la serie litográfica de los toros de Burdeos (Baticle, 2004: 370). También, es importante resaltar la obra litográfica de Toulouse-Lautrec, considerado el padre del cartel publicitario (Jiménez, 2012: 21).

Como indicamos al inicio de este artículo, la litografía fue la expresión artística más exitosa del proyecto "Arte para todos" (Langa, 2004: 43), cuyas repercusiones se hicieron sentir en la década de 1960, con el proyecto Tamarind, que revivió la litografía como una de las expresiones gráficas más emblemática de la segunda mitad del siglo XX (Antreasian y Adams, 1970: 464).

En nuestro contexto, en la Escuela de Bellas Artes, la litografía era considerada como un proceso engorroso, ya que requiere una serie de pasos para estabilizar el dibujo sobre la piedra, que en conjunto consumían unos tres días e involucraba muchos factores que podían arruinar el trabajo por lo cual, era necesario un método más simple y rápido. Otra vez la serendipia apareció en escena, con un proceso en el cual se emplea el jugo de limón ácido y la miel de abejas, como estabilizadores, en vez del ácido nítrico y la goma arábiga; lo cual, aparte de su carácter no tóxico, hace que el proceso pueda realizarse en menos de dos horas (HernándezChavarría, 2010, pp. 242-250). Actualmente, es la metodología en boga en la Escuela de Artes Plásticas, de la Universidad de Costa Rica. La figura 7 corresponde a una imagen litográfica realizada por el artista Alberto Murillo, quien redescubrió la magia de la litografía, gracias al limón y la miel de abejas. 


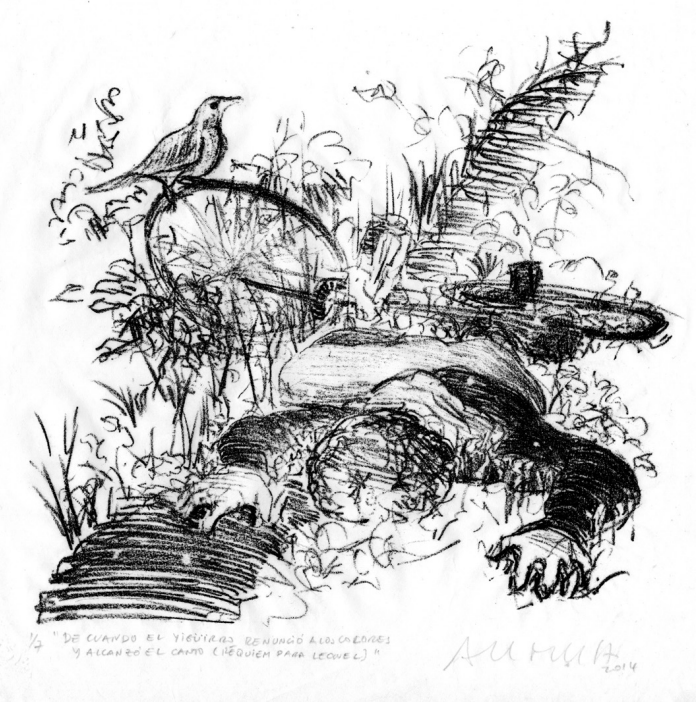

FIGURA 7.

Alberto Murillo. De cuando el yigüirro renunció a los colores y alcanzó el canto (Requiem para Leonel). 2014, litografía realizada con la técnica de limón y miel, 25 x $24 \mathrm{~cm}$.

\section{Serigrafía}

La serigrafía es una técnica de grabado e impresión de tipo permeográfica ya que se trabaja con una malla permeable a la tinta, sobre la cual se dibuja un diseño con un medio que impermeabiliza los trazos, lo que equivale a hacer un esténcil; por lo tanto, la tinta pasa selectivamente solo por las áreas que permanecen permeables o no bloqueadas y se imprime el diseño sobre un soporte determinado, como papel, tela, plástico, metal, entre otros. Se trata de un proceso sumamente mecánico y lineal por lo que esta técnica tiene un sinfín de aplicaciones, no solo artísticas y artesanales, sino también industriales.

Los argumentos anteriores, permiten concluir que la serigrafía se basa en transferir una imagen a un soporte, mediante un esténcil que bloquea selectivamente el paso de la tinta lo cual tiene antecedentes prehistóricos, como son las siluetas de manos en las cuevas de Altamira, España, entre otros sitios arqueológicos. En esas manifestaciones, las manos actuaron como esténcil, al bloquear un pigmento que se sopló a través de un cilindro hueco, que pudo ser un hueso o una caña. Una imagen actual, técnicamente similar, la constituyen algunos graffitis, que emplean un esténcil de papel recortado y una lata de pintura en aerosol. Sin embargo, las primeras imágenes propiamente serigráficas, datan de la antigua China, entre el año 500 y el 1000 a.C. y corresponden a imágenes de Buda realizadas mediante esténciles de papel recortado. Luego en Japón, en el siglo VI, en la Dinastia Sung, se desarrolló lo que se conoce como Kappazuri-e, que era un proceso de impresión por estarcido, en el cual se impermeabilizaban ciertas zonas de un marco tensado con cabellos o finos hilos de seda, de donde deriva el término serigrafía; luego, utilizando una brocha se traspasaba la tinta al soporte deseado. Esta técnica llegó a 
Francia, diez siglos después, bajo el nombre de pochoir; y se utilizó para imprimir barajas y naipes de hasta cuatro tonos, que pronto se volvieron parte de la cultura popular; aunque la técnica de estarcido nunca compitió realmente con la imprenta, creó un estilo paralelo, más barato y comercial, que permitía la impresión en superficies de tela y papel.

La serigrafía tuvo un gran crecimiento comercial en EEUU, durante el siglo XX; como se deduce de la patente de Charles N. Jones, en 1907, para un equipo constituido por un marco de madera, con una seda pretensada, una rasqueta o squegge, para traspasar la tinta y por supuesto, la tinta misma. Posteriormente, en la década de 1920, se desarrolló una película fotosensible autoadherible a la seda, lo que permitía, mediante un proceso de revelado fotográfico, crear esténciles indirectos en las mallas serigráficas. El desarrollo ulterior de las películas fotográficas para la impresión serigráfica, atrajo la atención de la industria y la serigrafía se convirtió en un proceso ágil y rápido, que permite estampar imágenes en muy diferentes sustratos, abriéndose al mundo textil y a una amplia gama de aplicaciones industriales.
En el contexto histórico del grabado, la serigrafía desplazó a la litografía, pues el tiempo que se requería para grabar una imagen era superado por la facilidad del revelado fotográfico. Así, la posibilidad de crear imágenes nunca había sido tan veloz y los artistas Pop de las décadas de 1950 y 1960 , la tomaron como estandarte para satirizar una sociedad norteamericana que se desbocaba hacia el consumo desmedido, brindándole las imágenes icónicas de representantes de esa reproductibilidad sin sentido, del vacío existencial y de la constante necesidad de crear ídolos fugaces. El ejemplo máximo EEUU es Andy Warhol y en Inglaterra Richard Hamilton (Tallman, 1996: 62) en ambos casos, las series de retratos intervenidos y las imágenes propias de la sociedad de consumo -para la cual la imagen serigráfica masificada es concebida como un objeto no coleccionablese convirtieron en un puente entre el objeto de consumo y el arte mismo, que sigue manteniendo actualidad, como lo demuestra la serie Objetos de nuestro tiempo de M Craig-Martin (Coldwell, 2014: 6) o la imagen recurrente del retrato manipulado como se aprecia en la figura 8 .

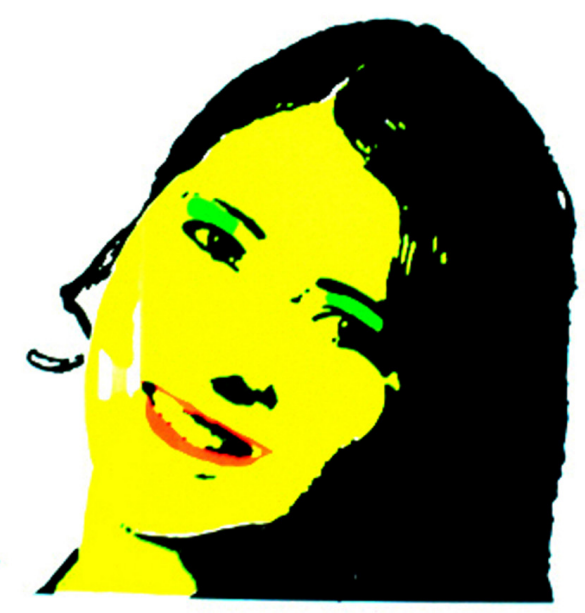

FIGURA 8.

Ólger Arias. Retrato de mi madre inspirada en el fetiche warholiano. 2014, serigrafía, 45 x $45 \mathrm{~cm}$ 
En el contexto del arte, la serigrafía se aparta un tanto del proceso mecanizado industrial, para abrirse a la expresión del artista, que entonces se recurre al sistema tradicional de la malla pretensada y una rasqueta, en un procedimiento manual, ya sea dibujando directamente en la malla o empleando métodos de fotosensibilización e imprimiendo en distintos soportes, desde lo tradicional en papel o tela, hasta otros menos convencionales como realizó Ólger Arias en la exposición de 2006 (a)Pareo anal-ógico, en la que se utilizó la técnica serigráfica y el método comercial de impresión con tinta de vinil, para estampar imágenes fotográficas intervenidas digitalmente, sobre láminas acrílicas.

\section{Conclusión}

El grabado y en especial el grabado en metal, fue considerado como una de las disciplinas del arte con mayor riesgo para la salud, tanto del artista como de su entorno, dado el uso de solventes derivados del petróleo y sustancias cáusticas, cuya lista era encabezada por el ácido nítrico. La historia, empero, cambió a partir de la década de 1990 y actualmente hay un movimiento de concientización internacional, que vela por una práctica del grabado cada vez más segura. La Escuela de Artes Plásticas de la Universidad de Costa Rica, es uno de los entes académicos que promulga esas políticas de bioseguridad, documentando, divulgando y publicando los métodos y sus adaptaciones al contexto de los países menos desarrollados, para estimular la práctica segura de esta disciplina (Hernández-Chavarría y Murillo, 2012: 167; Hernández-Chavarría 2015. En prensa).

En conjunto el grabado involucra acciones creativas que incluyen desde la gubia que violenta la madera, los procesos para corroer selectivamente el metal, la manipulación del cartón aglomerado, el mármol o la pantalla serigráfica; en todo caso, representa un amplio conjunto de posibilidades artísticas, cuya finalidad es la creación en una matriz y su posterior impresión en un determinado soporte y la imagen impresa es lo que finalmente denominamos grabado. En este contexto, los términos grabado y original múltiple u obra multiejemplar, se concatenan con los conceptos de sobreexposición, módulo, transferencia, unicidad y reproducción múltiple, que también involucra al panfleto, al cartel e incluso al textil impreso y a los más variados sustratos que puedan contener una imagen; obviamente, sin apartarse de las manifestaciones más tradicionales del grabado, que siguen siendo un ícono de esta disciplina, con ediciones limitadas y firmadas por el artista, que en la mayoría de los casos es el propio impresor. Por lo tanto, las diversas manifestaciones del grabado abren un amplio abanico de posibilidades para la expresión artística de la sociedad actual, solo limitadas por la imaginación del artista. Pero, su valoración y apreciación para disfrutarle como obra artística, requiere un conocimiento al menos básico de las técnicas involucradas, de los conceptos, de sus significados y de las cualidades estéticas que puede brindar cada una de las distintas metodologías involucradas en el grabado; por esa razón, este artículo pretende ser una concisa guía del conocimiento en grabado, para que cada vez, más personas aprecien y disfruten el grabado, como esa obra artística del original múltiple.

\section{Bibliografía}

Antreasian, Garo y Clinton, Adams. 1970. The Tamarind book of lithography: Art \& Techniques. Nueva York: Harry N. Abrams.

Astijnman, Ad. 2012. Engraving and etching 1400-2000. PaísesBajos:Archetype Publication.

Baticle, Jeannine. 2004. Francisco de Goya. Barcelona: Printer Industria Gráfica.

Coldwell, Paul. 2014. "An artist of our time. Michael Craig-Martin RA". En: Printmaking Today, XXIII (2), 6-7. 
Ivins, William. 1975. Imagen impresa y conocimiento. Análisis de la imagen prefotográfica. Barcelona: Editorial Gustavo Gil.

Hernández-Chavarría, Francisco y Patricia Rivera. 2001. "Serendipia e investigación en Microbiología". En: Revista Colegio de Microbiólogos Químico Clínicos, Costa Rica, VIII (1): 6-9.

Hernández-Chavarría, Francisco. 2011. "Con limón y miel: Una litografía alternativa, simple y rápida". En: El Artista, VIII: 242-250.

Hernández-Chavarría, Francisco y Alberto, Murillo. 2012. "Cinco años de abstinencia de todo ácido: La experiencia del grabado no tóxico en la Escuela de Artes Plásticas de la Universidad de Costa Rica”. En: Arte Individuo y Sociedad, XXIII (2): 167-177.

Hernández-Chavarría, Francisco. 2014. “Un mordente, un electrolito y grabado en cualquier metal". En: El Artista XI: 181-188.
Hernández-Chavarría, Francisco. 2015. “Aportes al grabado en metal: Escuela de Artes Plásticas”. En: El Artista, 12 En prensa.

Jiménez, Fernando. 2012. Cartel. México D. F.: Red Tercer Milenio.

Langa, Helen. 2004. Radical Art. Printmaking and the leaf in 1930's New York. California:University of California Press.

Senefelder, Alois. 1819. A complete course of lithography by AloisSenefelder with an introduction by A Hyatt Mayor, curator emeritus of Print Metropolitan Museum of Art and a supplement of thirty-one plates from the first German and French editions. Nueva York. Da CappPress.

Talbot F, William Henry. 2011. The Pencil of Nature, London, 1844.Text auch auf http://www.thepencilofnature.com/, Stand vom, 10.

Tallman, Susan. 1996. The Contemporary Print: From Pre-Pop to Postmodern. Londres. Thames and Hudson.

\section{@() $\Theta \Theta \Theta$}

Este obra está bajo una licencia de Creative Commons Reconocimiento-NoComercial-SinObraDerivada 4.0 Internacional. 